\title{
Placenta percreta in primigravida, an unsuspected situation
}

\author{
Bhuvaneshwari Rajkumar ${ }^{1 *}$, Nisha Kumar $^{1}$, Sowmya Srinivasan ${ }^{2}$ \\ ${ }^{1}$ Department of Obstetrics \& Gynecology, Sri Manakula Vinayagar Medical College and Hospital, \\ Kalitheerthalkuppam - 605107, Puducherry, India \\ ${ }^{2}$ Department of Pathology, Sri Manakula Vinayagar Medical College and Hospital, Kalitheerthalkuppam - 605107, \\ Puducherry, India
}

Received: 13 November 2013

Accepted: 9 December 2013

*Correspondence:

Dr. Bhuvaneshwari Rajkumar,

E-mail: zoomtobhuvan@gmail.com

(C) 2014 Rajkumar B et al. This is an open-access article distributed under the terms of the Creative Commons Attribution Non-Commercial License, which permits unrestricted non-commercial use, distribution, and reproduction in any medium, provided the original work is properly cited.

\begin{abstract}
Placenta percreta, the most severe form of placenta accreta, is a rare pregnancy disorder in which the placenta penetrates the uterine myometrium and serosa and can invade the surrounding organs. It is a potentially lifethreatening condition with risk of severe maternal morbidity and mortality. Although recognized obstetric risk factors allow the identification of most cases during the prenatal period, diagnosis is occasionally made at the time of delivery. Both sonography and MRI have fairly good sensitivity for prenatal diagnosis of placenta accreta. Prenatal diagnosis allows management of these patients in specialized tertiary centers, where a multidisciplinary approach will improve the outcome. Even in undiagnosed cases discovered at the time of delivery involving a team of anesthesiologist, obstetrician, urologist, neonatologist, and blood bank officer is needed for successful management of these patients. In this report we present the case of a primigravida with no known risk factors who was diagnosed to have placenta percreta at the time of caesarean delivery.
\end{abstract}

Keywords: Placenta percreta, Retained placenta, Caesarean hysterectomy, Emergency hysterectomy, Third stage hemorrhage

\section{INTRODUCTION}

Adherent placenta accounts for $7-10 \%$ of maternal mortality cases worldwide. ${ }^{1}$ Placenta accreta occurs when the chorionic villi invade the myometrium abnormally. It is classified according to degree of invasion into the myometrium as placenta accrete vera, placenta increta and placenta percreta, with placenta percreta being the most severe but least common one. ${ }^{2}$ Women who are considered at risk of adherent placenta are those with placenta previa, 2 or more caesarean deliveries, ${ }^{4}$ advancing maternal age ( $\geq 35$ yrs), second-trimester serum levels of AFP and free $\beta$-hCG greater than 2.5 multiples of median, ${ }^{3}$ previous uterine surgery, previous uterine curettage, multiparity and high gravidity. ${ }^{5}$ Here, we present the case of 30 yrs old primi gravid with no known risk factors diagnosed intraoperatively to have placenta percreta.

\section{CASE REPORT}

A 30 year old booked primigravida was admitted to labour room with preterm premature rupture of membranes at 35 weeks +2 days of gestation. Her antenatal period was uneventful prior to admission. Her past medical and surgical history was not significant. At the time of admission her hemoglobin was $11.2 \mathrm{gms} / \mathrm{dl}$, hematocrit $33 \%$ and coagulation profile was normal. Prenatal ultrasound was taken and amniotic fluid index was found to be 3. Labor was induced in view of oligohydramnios. Patient was taken up for emergency caesarean section under spinal anaesthesia in view of failed induction. A preterm male baby of $2.2 \mathrm{~kg}$ was delivered. The placenta however, could not be removed with gentle traction. Manual removal of placenta was attempted. After partial placental removal, plane of separation could not be identified between uterine wall 
and placenta. Uterus was exteriorized. The fundal portion and left cornu of the uterus appeared to be bulging; spongy and hemorrhagic (Figure 1). A diagnosis of partial placenta percreta was made. In view of excessive bleeding from the placenta separation site, emergency caesarean hysterectomy was proceeded with. Total blood loss was estimated to be $2000 \mathrm{ml}$. 2 units of cross matched blood was transfused intra operatively. Operated specimen was sent for histopathological examination. Postoperatively the patient was admitted to surgical intensive care unit for $24 \mathrm{hrs}$ and transferred to ward later. Histopathological examination showed chorionic villi within myometrium and transmural trophoblastic infiltration sparing a thin rim of serosa (Figure 2). Postoperative period was uneventful and patient was discharged with a healthy baby, after suture removal.

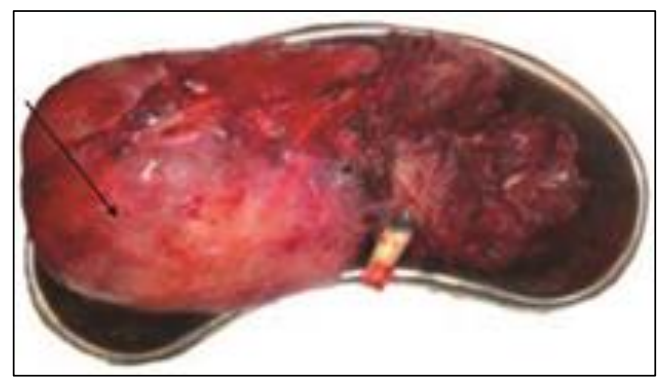

Figure 1: Fundal portion and left cornu of the uterus infiltrated with placental tissue up to the serosal surface and appears bulging, spongy and hemorrhagic.

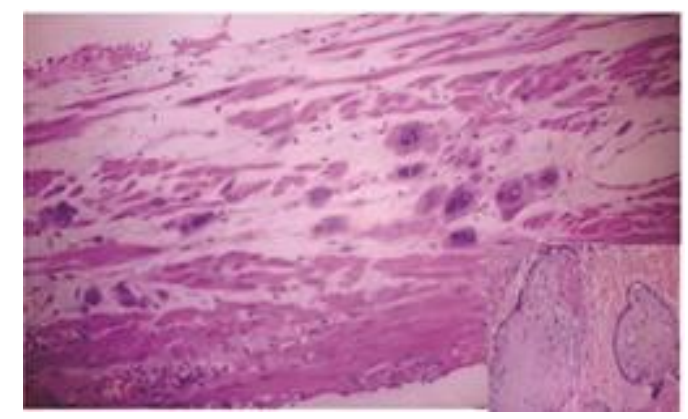

Figure 1: Microscopic appearance showing transmural trophoblastic infiltration; arrow- serosa; Inset: chorionic villi within myometrium, H \& E; 40x.

\section{DISCUSSION}

The incidence of placenta accreta has increased from one in 2500 in the 1970 s and 1980 s to one in 533 in $2000 .^{4}$ Placenta percreta accounts for only $5 \%$ of adherent placenta while $75 \%$ to $80 \%$ are placenta accreta vera and $17 \%$ are placenta increta. ${ }^{2}$ Over the last four decades, adherent placenta is becoming an increasingly common indication for peripartum hysterectomy, rising from $5.4 \%$ to $46.5 \%{ }^{6}$ The incidence is rising primarily because of the rise in caesarean delivery rates. Our case has been presented here because of the rare occurrence of placenta percreta in primi gravida without any known risk factors.
Review of literature has shown only 2 cases of primigravida with placenta accreta. A case of placenta increta in primipara has been reported by Arnadottir BT et al. $^{7}$ that has ended in delivery of a healthy infant with successful conservative management with methotrexate. Kinoshita et al. ${ }^{8}$ from Japan, reported one case of spontaneous rupture of uterus due to placenta percreta in a primi gravid without a background of any risk factor, similar to the our case in its occurrence.

\section{Diagnosis}

Prenatal diagnosis seems to be a key factor in optimizing maternal outcome. Diagnosis can be achieved by ultrasound in the majority of the cases of adherent placenta. ${ }^{9}$ Ultrasound findings that may suggest a possibility of adherent placenta in first trimester are low lying gestational sac attached to the uterine scar and thinning of myometrium in the area of scar where the sac is attached. ${ }^{10}$ Women with such ultrasound findings in first trimester should be followed up for the potential presence of placenta accrete. ${ }^{11}$ Findings which suggest placenta accreta by ultrasound later in pregnancy are loss of retroplacental hypoechoic clear zone, loss of interface between bladder wall and uterus, presence of placental lacunae (vascular spaces) and increased vascularity of the interface between the bladder wall and uterine serosa on colour doppler imaging. ${ }^{12}$

If the ultrasound findings are not considered definitive or the placenta is located on the posterior wall, magnetic resonance imaging can be performed. Controversy surrounds the use of gadolinium - based contrast enhancement though it improves the specificity of MRI diagnosis of placenta accreta, because of the possible fetal effects, as it crosses the placenta and readily enters the fetal circulation. ${ }^{13}$ The American college of Radiology guidance document for safe MRI practices ${ }^{14}$ recommends that intravenous gadolinium should be avoided during pregnancy unless it is absolutely essential. Although our patient underwent multiple antenatal ultrasonography examinations, adherent placenta was not diagnosed probably due to fundal location.

\section{Obstetric management}

Women with any type of adherent placenta should be treated in specialized tertiary care hospital. ${ }^{15}$ The recommended management of placenta percreta is planned caesarean hysterectomy at 34 - 35 weeks with intact placenta. ${ }^{13}$ A multidisciplinary approach by a team of experienced obstetricians, anesthesiologists, neonatologists and urologists, as well as a blood bank helps in achieving the best outcome. ${ }^{16}$

Conservative management of placenta percreta includes removing the cord and leaving the placenta in utero, potentially with partial placental resection to minimize the size. This approach should be considered only when the patient has a strong desire to retain her fertility and she is hemodynamically stable with normal coagulation 
status and is willing to accept the risk involved in the conservative management. ${ }^{13}$ Complications that can occur with conservative management are severe postpartum hemorrhage, post-operative coagulopathy and antimicrobial resistant infection that may require relaparotomy and hysterectomy. ${ }^{9}$ The role of methotrexate in post-partum management adherent placenta is uncertain, though some cases have been reported. ${ }^{13}$ Preoperative placement of occlusion catheter with intraoperative balloon occlusion of the aorta, common iliac, hypogastric and uterine arteries has been found to control obstetric hemorrhage. Because of the extensive collateral blood supply to the uterus from branches of the obturator, lumbar, sacral, rectal, and femoral arteries, intravascular occlusion proximal to the uterine is preferred. But occlusion of larger vessels like the aorta and common iliac arteries may result in ischemia of the lower extremities. In such cases, monitoring of blood pressure and serial blood gas analysis in the lower extremities and occasional deflation of the balloon prevented distal ischemia. ${ }^{17}$ Balloon occlusion of the internal iliac arteries is most commonly followed ${ }^{18}$ even though some blood loss will occur due to extensive pelvic collaterals. ${ }^{17}$ Caesarean hysterectomy is probably the preferable treatment and conservative management should only be used in highly selected cases and in places where such facilities are available.

\section{ACKNOWLEDGEMENTS}

The authors would like to acknowledge Dr. Shubhada Anand Patil, the anaesthetist for her support during surgery.

Funding: No funding sources Conflict of interest: None declared

Ethical approval: Not required

\section{REFERENCES}

1. Chandraharan E, Rao S, Belli AM, Arulkumaran S. The Triple-P procedure as a conservative surgical alternative to peripartum hysterectomy for placenta percreta. Int J Gynaecol Obstet. 2012;117(2):191-4.

2. Konijeti R, Rajfer J and Askari A. Placenta Percreta and the Urologist. Rev Urol. 2009;11(3):173-6.

3. Hung TH, Shau WY, Hsieh CC, Chiu TH, Hsu JJ, Hsieh TT. Risk factors for placenta accrete. Obstetrics and Gynecology. 1999;93(4):545-50.

4. Wu S, Kocherginsky M, Hibbard JU, Abnormal placentation twenty-year analysis. Am J Obstet Gynecol. 2005;192(5):1458-61.

5. Jacques SM, Qureshi F, Trent VS, Ramirez NC. Placenta accreta Mild cases diagnosed by placental examination. Int J Gynecol Pathol. 1996;15:28-33.
6. Flood KM, Said S, Geary M, Robson M, Fitzpatrick $\mathrm{C}$, Malone FD. Changing trends in peripartum hysterectomy over the last 4 decades. Am J Obstet Gynecol. 2009;200(6):632 e1-6.

7. Arnadottir BT, Hardardóttir H, Marvinsdóttir B. Case report seventeen year old primipara with placenta increta treated with methotrexate. Laeknabladid. 2008;94(7-8):549-52.

8. Kinoshita T, Ogawa K, Yasumizu T, Kato J. Spontaneous rupture of the uterus due to placenta percreta at 25-weeks of gestation: a case report. Journal of Obstetrics and Gynaecology Research. 1996;22(2):125-8.

9. Hudon L, Belfort MA, Broome DR. Diagnosis and management of placenta percreta: a review. Obstet Gynecol Surv. 1998;53(8):509-17.

10. Comstock $\mathrm{CH}$. Antenatal diagnosis of placenta accreta: a review. Ultrasound in Obstetrics and Gynecology. 2005;26(1):89-96.

11. Belfort MA. Placenta accrete. American Journal of Obstetrics \& Gynecology. 2010;203:430-9.

12. Comstock CH, Love Jr JJ, Bronsteen RA, Lee W, Vettraino IM, Huang RR, Lorenz RP. Sonographic detection of placenta accreta in the second and third trimesters of pregnancy. Am J Obstet Gynecol. 2004;190:1135-40.

13. American College of Obstetricians and Gynecologists; ACOG Committee opinion No. 529. Placenta accrete. Obstet Gynecol. 2012;120:207-11.

14. Kanal E, Barkovich AJ, Bell C, Borgstede JP, Bradley WG et al. ACR guidance document for safe MR practices: ACR Blue Ribbon Panel on MR Safety. AJR Am J Roentgenol. 2007;188:1447-74.

15. Eller AG, Bennett MA, Sharshiner M, Masheter C, Soisson AP, Dodson M, Silver RM. Maternal morbidity in cases of placenta accreta managed by a multidisciplinary care team compared with standard obstetric care. Obstet Gynecol. 2011;117:331-7.

16. Sivasankar C. Perioperative management of undiagnosed placenta percreta: case report and management strategies. International journal of Women's health. 2012;4:451-4.

17. Knuttinen MC, Jani A, Gaba RC, Bui JT, Carrillo TC. Balloon Occlusion of the Hypogastric Arteries in the Management of Placenta Accreta: A Case Report and Review of the Literature. Semin Intervent Radiol. 2012 Sep;29(3):161-8.

18. Kidney DD, Nguyen AM, Ahdoot D, Bickmore D, Deutsch LS, Majors C. Prophylactic perioperative hypogastric artery balloon occlusion in abnormal placentation. AJR Am J Roentgenol. 2001;176(6):1521-4.

DOI: $10.5455 / 2320-1770 . i j r \operatorname{cog} 20140349$

Cite this article as: Rajkumar B, Kumar N, Srinivasan S. Placenta percreta in primigravida, an unsuspected situation. Int J Reprod Contracept Obstet Gynecol 2014;3:239-41. 